\title{
Green networks: a solution to the Urban Heat Island effect
}

\author{
C. Johnson \\ School of the Built Environment, University at Salford, UK
}

\begin{abstract}
According to the United States Environmental Protection Agency, an Urban Heat Island is created in developed areas where the built surfaces absorb and retain radiation from the sun. These impervious surfaces prevent the movement of air and water which are key in the cooling processes of evaporation and transpiration; and create proverbial 'urban islands' of warmer temperatures while the green vegetation in the surrounding rural areas better regulate surface temperatures. The impacts of Urban Heat Islands include increased energy consumption, higher concentration of air pollutants and poorer water quality. Throughout the Caribbean, increased energy consumption levels exacerbates the strain on the electric grid, reduces the strength of electrical output and increases in the frequency of power outages. Heated air also fosters a higher concentration of air pollutants and promotes the creation of ground level ozone which triggers a number of health related problems including coughing and throat irritation and exacerbate the effects of emphysema, asthma and bronchitis. Lastly, heated urban surfaces encourage higher temperatures in storm water that reduce the dissolved oxygen in the water of surrounding rivers and oceans. To mitigate this problem Caribbean countries have developed renewable energy strategies, but there is another solution to address the impact of higher surface temperatures. The American Society of Landscape Architects describes green infrastructure as an integrated network of open spaces that foster the generation of clean air, water and carbon sinks. An analysis of international case studies will highlight the ways in which the inclusion of green networks in Caribbean urban areas can help reduce surface temperatures, manage our energy consumption and improve air and water quality.

Keywords: Urban Heat Islands, ground level ozone, local climate zone, green networks, green roofs.
\end{abstract}




\section{Introduction}

Urban Heat Islands (UHI) are created when significantly warmer surface temperatures exist in urban settings as opposed to their surrounding rural areas. Based on the impact of anthropogenic activities, the characteristics of warmer urban climates are not but limited to increase levels of ground level ozone and higher concentrations of particulate matter in the form of pollution. UHI can be identified as a direct result of the urban form and function. The magnitude of UHI during the year is predetermined by the climate of a particular geographical location. In tropical climates the higher magnitude of UHI is during the dry seasons as UHI is more likely to occur during temperatures are skies are clear and not windy [1]. In addition, unregulated development in Latin America and the Caribbean are significant contributors to the increasing levels of UHI magnitude.

Through a comprehensive analysis of existing literature this paper underlines the definition and parameters of urban heat islands by pointing out how ground level ozone and urban morphology contribute to the UHI magnitude. A review of a local climate zone methodology to assist in the determination of UHI magnitude highlights an accessible method of identifying UHI magnitude in the absence of extensive scientific research. Before determining the ways to address the magnitude of UHI, understanding the spatial structure of a particular urban setting is important.

Based on the existing research, the most effective strategy for addressing urban heat islands is chronicled as the development of green networks. The inclusion of green networks within an urban setting fosters opportunities for evapotranspiration processes and increasing the surface albedo [2] to cool the increase in surface temperatures caused by heated impervious surfaces. Studies have proven that the principles green networks can reduce the magnitude of UHI in urban settings as they provide opportunities for the cooling of temperatures and disbursement of pollution.

The paper seeks to strengthen regional understanding of UHI, provide viable options for determining UHI magnitude and highlight the framework for addressing UHI in the region.

\section{Urban Heat Islands}

The study of Urban Heat Islands (UHI) is based on the premise that significantly warmer surface temperatures exist in urban settings as opposed to their surrounding rural areas. Urban settings are a conglomeration of the burning of fossil fuel for energy and transportation and impervious surfaces in the forms of roads and buildings. The exponential growth of cities exacerbate these issues as larger collections of people concentrate in smaller geographic areas. Urban heat islands are now expanding into urban archipelagos and all that comes along with the conditions expand the heated areas across larger geographical areas. Based on the impact of these anthropogenic activities, the characteristics of warmer 
urban climates are not but limited to increase levels of ground level ozone and higher concentrations of particulate matter in the form of pollution.

This increase in surface temperatures is a result of the absorption characteristics of the urban morphology. Albedo is the ability of a material to reflect radiation of the sun. Lower albedo suggests that the surface of the material absorbs the majority of radiation and is typical of dark colored materials. Higher albedo suggests that the surface reflects the majority of radiation and is typical of light colored materials [3]. The absorption of radiation by the surfaces in the urban environment then have an impact on the rate of radiation released and the surface temperatures.

Short wave radiation is the ultraviolet rays produced by the sun. During the day, built impervious surfaces absorb a portion of these shortwave radiation and reflect a portion. The absorbed radiation contributes to warmer conditions of the urban environment, increase the use of energy to restore thermal comfort and is commonly what is thought of in the understanding of UHI. At night, however the built surfaces are cooler and the absorbed radiation is released in longer waves through infrared rays. The form of radiation is more significant in nocturnal UHI as the released radiation cannot improve surface temperatures since the longwave radiation is reabsorbed by the same low albedo surfaces.

The determination of UHI magnitude in an urban setting is categorized into the urban canopy layer and the urban boundary layer [4]. The urban canopy layer is the air between the ground and roof of buildings, where the ground level ozone is prevalent. In this layer the air is dominated by radiation from the buildings and the direct emissions from transportation. The UHI magnitude within the canopy layer is typically filled with a dense collection of pollutants and can be comprised when stronger air allows air from the above infiltrate the canopy [4]. It is not definite line as the typical urban skyline has varying building heights and an urban canopy layer does not exist in vegetated, open spaces. In the midst of dense urban environments, the canopy layer sits below the roof level of the city; in an open space the canopy layer is non-existent. The urban boundary layer is from the roof or the urban area to the point at which there is an inversion of temperatures clearly delineating a boundary to the limits of the urban pollution [4]. The warmer air in these two layers fosters less movement of heavier particles in the air and encourages the concentration of ground level ozone.

\subsection{Ground level ozone}

Within the urban canopy layer ozone is a pollutant formed as a result of a photochemical reaction to nitrogen oxide and other volatile organic chemicals creating $\mathrm{O}_{3}$ [5]. During the dry season in the Caribbean region when the temperatures are warm for consecutive days and the air remains stagnant the levels of $\mathrm{O}_{3}$ are increased. Considering the contribution to pollution from industry activity and transportation emissions, levels of ozone may differ from country to country. This pollutant is causes irritation to the human respiratory systems, impairing lung function, fostering chronic lung disease such as emphysema and bronchitis and asthma and damaging the lining of the lung [6]. 
UHI are a result of the urban form and function, weather and geography therefore no two cities have the same UHI characteristics. Tracking metrological activity and monitoring form and function of urban areas in are the key determinants in understanding the extent of UHI that exist in a particular area.

\subsection{Urban morphology}

The spatial structure and function of a city is however at the center of the occurrence of UHI. The structure of a city is determined by the density in the arrangement of the structures-; the thermal properties of the construction material, and number of opportunities for greenspace within the city limits [1]. Density is a result of the number of structures within a prescribed area, the spaces between buildings as a result of the width of streets, alleyways and site coverage regulations. Impervious, dark colored building and infrastructure materials create surfaces that encourage the heating of surface temperatures. Cities with wide street networks as a function of more accessible transportation routes can have high magnitudes of UHI than cities that retain their historic, smaller street networks. The correlation between the city's function and UHI magnitude are particularly the contribution of anthropogenic heat [1].

UHI are at the strongest magnitude when the skies are clear and calm but as the presence of the wind mixes the stagnancy of the air and reduces the concentrate of pollution as well as the heat island. Increased rain activity increase assists with the cooling process of warmed surfaces and also provide a blockage from the sun's radiation. Therefore the seasons of the geographical location determine the magnitude of the UHI during the annual cycle. In mid latitude climates the instances of UHI typically occur in the summer and winter months versus tropical climates where UHI is more prevalent during the dry seasons [1].

\section{Local/micro climate zone}

Although these anthropogenic activities have an impact on urban environments, not all UHIs are alike. Understanding the spatial structure of a particular urban setting is important to effectively address the magnitude of UHI. In particular climates deciduous trees are better suited because the provide shade in the summer to reduce the impact of the UHI but fallen leaves during the winter allow for more sunlight to increase the magnitude of UHI to reduce the strain on the energy use to heat the buildings.

Understanding the Local Climate Zone (LCZ) characteristics of a region can provide guidance of the development of adaptation tools. Building upon the work of T.R. Oke's Urban Climate Zones where attention was placed in determining the surface roughens - the distribution of buildings heights within the urban setting and the ratio of impermeable to permeable surfaces [4], LCZ to create a method classify the UHI magnitude of an urban setting. It highlights the UHI magnitude based on an examination of the urban setting landscape and develops classes to emphasize a local scale, the nature of the climate within the 
zones. The LCZ system reviews the surface disturbance as a result of the inclusion of impervious surfaces in the natural, native landscape [7]. Table 1 illustrates the definition of local climate zones - LCZ 1-10 are built types as they categorize the development landscape in urban areas, LCZ A-G are the land cover types as a reflection of the native landscape.

Table 1: Local climate zone designations.

\begin{tabular}{|c|c|c|c|}
\hline Built types & Definition & Land cover types & Definition \\
\hline 1. Compar & $\begin{array}{l}\text { Dense mix of tall buildings to tens of } \\
\text { stories. Few or no trees. Land cover } \\
\text { mostly paved. Concrete, steel, stone. } \\
\text { and glass construction materials. }\end{array}$ & A. Dense trees & $\begin{array}{l}\text { Heavily wooded landscape of } \\
\text { deciduous andior evergreen trees. } \\
\text { Land cover mostly pervious (low } \\
\text { plants). Zone function is natural } \\
\text { forest, tree cultivation, or urban park. }\end{array}$ \\
\hline 2. Com & $\begin{array}{l}\text { Dense mix of midrise buildings (3-9 } \\
\text { stories). Few or no trees. Land cover } \\
\text { mostly paved. Stone, brick, tile, and } \\
\text { concrete construction materials. }\end{array}$ & B. Scattered trees & $\begin{array}{l}\text { Lightly wooded landscape of } \\
\text { deciduous andior evergreen trees. } \\
\text { Land cover mostly pervious (low } \\
\text { plants). Zone function is natural } \\
\text { forest, tree cultivation, or urban park. }\end{array}$ \\
\hline 3. Compact low-rise & $\begin{array}{l}\text { Dense mix of low-rise buildings ( } 1-3 \\
\text { stories). Few or no trees. Land cover } \\
\text { mostly paved. Stone, brick, tile, and } \\
\text { concrete construction materials. }\end{array}$ & C. Bush, scrub & $\begin{array}{l}\text { Open arrangement of bushes, shrubs, } \\
\text { and short, woody trees. Land cover } \\
\text { mostly pervious (bare soll or sand). } \\
\text { Zone function is natural scrubland or } \\
\text { agriculture. }\end{array}$ \\
\hline 4. Open & $\begin{array}{l}\text { Open arrangement of tall buildings to } \\
\text { tens of stories. Abundance of pervious } \\
\text { land cover (low plants, scattered } \\
\text { trees). Concrete, steel, stone, and } \\
\text { glass construction materials. }\end{array}$ & D. Low plants & $\begin{array}{l}\text { Featureless landscape of grass or } \\
\text { herbaceous plantsicrops. Few or } \\
\text { no trees. Zone function is natural } \\
\text { grassland, agriculture, or urban park. }\end{array}$ \\
\hline 5. Open midrise & $\begin{array}{l}\text { Open arrangement of midrise buildings } \\
\text { (3-9 stories). Abundance of pervious } \\
\text { land cover (low plants, scattered } \\
\text { trees). Concrete, stoel, stone, and } \\
\text { glass construction materials. }\end{array}$ & E. Bare rock or paved & $\begin{array}{l}\text { Featureless landscape of rock or } \\
\text { paved cover. Few or no trees or } \\
\text { plants. Zone function is natural desert } \\
\text { (rock) or urban transportation. }\end{array}$ \\
\hline 6. Open low-rise & $\begin{array}{l}\text { Open arrangement of low-rise buildings } \\
\text { ( } 1-3 \text { stories). Abundance of pervious } \\
\text { land cover (low plants, scattered trees). } \\
\text { Wood, brick, stone, tile, and concrete } \\
\text { construction materials. }\end{array}$ & E. Bare soil or sand & $\begin{array}{l}\text { Featureless landscape of soll or sand } \\
\text { cover. Few or no trees or plants. } \\
\text { Zone function is natural desert or } \\
\text { agriculture. }\end{array}$ \\
\hline & $\begin{array}{l}\text { Dense mix of single-story bulldings. } \\
\text { Few or no trees. Land cover mostly } \\
\text { hard-packed. Lightweight constifuction } \\
\text { materials (e.g- wood, thatch, } \\
\text { corrugated metal). }\end{array}$ & G. Water & $\begin{array}{l}\text { Large, open water bodies such as seas } \\
\text { and lakes, or small bodies such as } \\
\text { rivers, reservoirs, and lagoons. }\end{array}$ \\
\hline 8. Large & $\begin{array}{l}\text { Open arrangement of large low-rise } \\
\text { buildings ( } 1-3 \text { stories). Few or no } \\
\text { trees, Land cover mostly paved. } \\
\text { Steel, concrete, mecal, and stone } \\
\text { construction materials. }\end{array}$ & \multicolumn{2}{|c|}{$\begin{array}{l}\text { VARIABLE LAND COVER PROPERTIES } \\
\text { Variable or ephemeral land cover properties that change } \\
\text { significantly with synoptic weather patterns, agricultural practices, } \\
\text { and/or seasonal cycles. }\end{array}$} \\
\hline 9. Spar & $\begin{array}{l}\text { Sparse arrangement of small or } \\
\text { medium-sized buildings in a natural } \\
\text { setting. Abundance of pervious land } \\
\text { cover (low plants, scattered trees). }\end{array}$ & 5. snow cover & $\begin{array}{l}\text { Leafless deciduous trees (e. \&. winter). } \\
\text { Increased sky view factor. Reduced } \\
\text { albedo. } \\
\text { Snow cover }>10 \mathrm{~cm} \text { in depth. Low } \\
\text { admittance. High albedo. }\end{array}$ \\
\hline 10. Heavy industry & $\begin{array}{l}\text { Low-rise and midrise industrial struc- } \\
\text { tures (towers, tanks, stacks). Few or } \\
\text { no trees. Land cover mostly paved } \\
\text { or hard-packed. Metal, steel, and } \\
\text { concrete construction macerials. }\end{array}$ & $\begin{array}{l}\text { d. dy ground } \\
\text { w. wet ground }\end{array}$ & $\begin{array}{l}\text { Parched soil. Low admittance. Large } \\
\text { Bowen ratio. Increased albedo. } \\
\text { Waterlozged soil. High admittance. } \\
\text { Small Bowen ratio. Reduced albedo. }\end{array}$ \\
\hline
\end{tabular}

The urban zones are sub categorized into six sections. Compact is defined as the dense arrangement of buildings allowing for minimal flow of air based on high to low floor to area ratio and the use impervious construction material. Open highlights the arrangement of the buildings to facilitate the movement of 
air based on aforementioned floor to area ratios also utilizing impervious construction material. Lightweight low rise is distinct in the use of penetrable construction materials such as wood, thatch and corrugated metal but a dense arrangement of the buildings. Sparsely built reflects the typical suburban setting in the sparse distribution of buildings with larger accommodation for pervious surfaces. Heavy industry accommodates for the industrial uses within the urban setting where all the land is typically covered by impervious surfaces.

The land cover zones are divided into seven categories largely emphasized in the functionality of each zone - dense trees - forested areas; scattered trees urban parks; bush, scrub - semi-arid scrubland or agricultural land; low plantsgrassland; bare rock or paved - urban transportation; bare soil or sand - deserts and; water - open bodies of water including reservoirs. The climate classification determines how the seasons can alter the magnitude of the UHI particularly surface albedo. Broken into four categories, bare trees refer to the leafless trees during seasonal changes particularly winter or the dry season; snow cover reflects the snow greater than $10 \mathrm{~cm}$ in depth; dry ground is parched soil and wet ground is waterlogged soil [8].

One LCZ classification of particular interest in developing regions like Latin American and the Caribbean is the LCZ 7 - Lightweight Low Rise. Its form is compactly arranged single storey, attached or detached buildings separated by narrow roads and alleyways. There is limited infrastructure and the buildings materials are thin construction materials making the walls and roofs of the structures unstable. The function of these classification is the informal settlements apply referred to as shantytowns or slums. According to the geometric data of the classification these areas are significant contributors to the UHI magnitude in LAC urban areas. LCZ 7 building surface fraction, which is the ratio of building plan area to total plan area is the highest among the other classifications, while its pervious surface fractions, i.e. ratio of permeable surface to the total plan area could be greater than the rating for compact high-rise.

Obtaining the LCZ is a function of examining the characteristics of the urban setting and the system prescribes geometric properties that are typically found in that zone. A comparison of LCZ 1 - Compact Low Rise and LCZ A - dense trees indicated the ways LCZ can inform the UHI impact in a particular area. These two categorizes have the same rating in terms of terrain roughness as the height variations of structures and trees are irregular creating large disparities overall height of the zone. However they differ greatly in pervious surface fraction LCZ 1 rating is less than 10 while LCZ A rating can exceed 90 exceeds and in anthropogenic output determined by fuel use from human activity and measured in $\mathrm{W} \mathrm{m}^{-2}$ for $\mathrm{LCZ} 1$ ranges from $50-300$ while LCZ A rating is zero. Figure 1 [8] illustrates the combination of the LCZ subclasses as step towards determining the characteristics of urban setting.

The classification system is not meant to replace the collection of data, but serves as a guide to examine the UHI magnitudes based on local conditions. It is meant to provide an examination of the landscapes influence on the surface temperature of urban settings. Determining the conditions of an urban area will provide insight into the necessary solutions to address the impacts of UHI. In the 


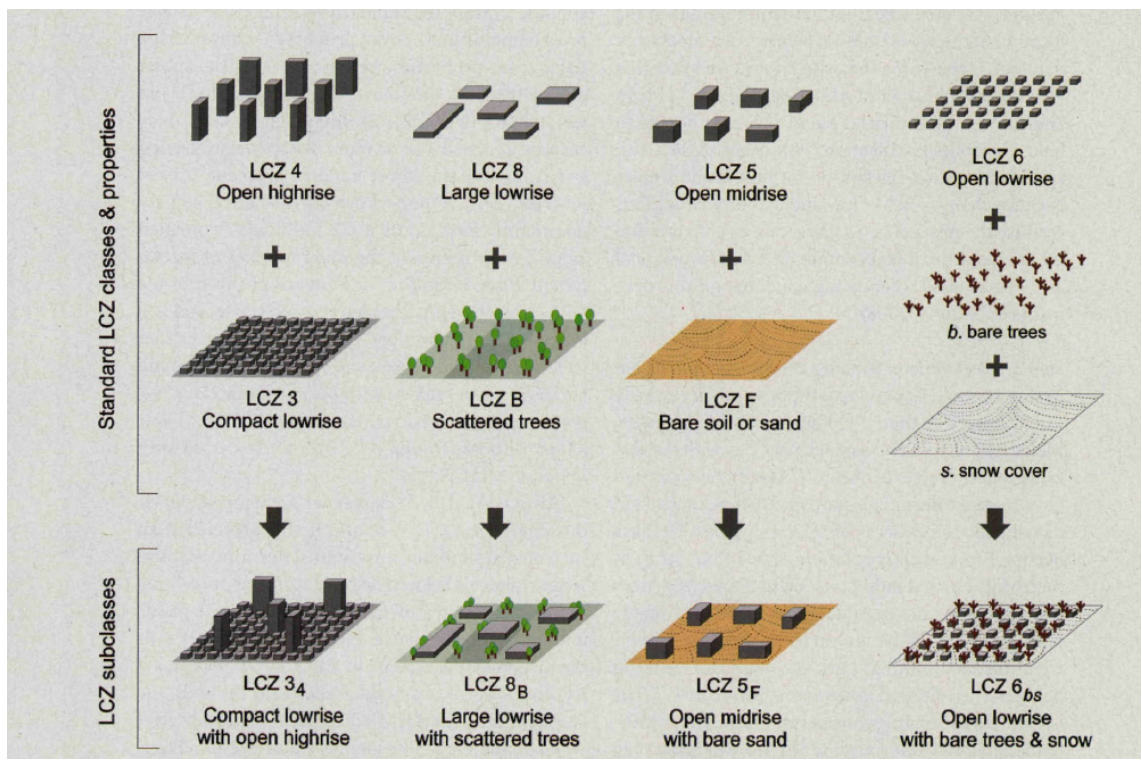

Figure 1: Local climate zone classes.

classification system the areas that received the highest rating for permeability and lowest anthropogenic heat output were the land cover categories with trees, bare soil and water. These types of land cover are very capable of reducing the impacts of UHI and therefore warrants further examination.

\section{Green networks}

The American Society of Landscape Architects describes green infrastructure as an integrated network of open spaces that foster the generation of clean air, water and carbon sinks [9]. The concentration of the pollutants within the urban canopy layer can be reduced by the inclusion of trees as they provide spaces within the urban form to facilitate the passage of air and disbursement of pollution. The inclusion of green spaces within an urban setting can place an integral role in reducing the impact of UHI by increasing opportunities for evapotranspiration processes and increasing the surface albedo [2].

\subsection{Street trees}

The rate at which heat penetrates a building determines the heat exchange behind the building and surroundings [10]. Due to the process of evapotranspiration, the presence of shade trees encourage the "oasis effect", cooling the surface temperatures significantly. The buildings surrounding these trees consume less energy to cool the interior rooms and increase the comfort for the surrounding environment. The best arrangement of the shade trees in an urban environment is an urban park. The arrangement of trees in the one areas allows for a greater 
impact to reduce the effects of UHI and lower the surface temperatures [11]. Parks are able to have this type of impact as there are a greater density of trees with zero anthropogenic heat outputs [8]. With an increase in parks in an urban setting the UHI magnitude can be mitigated through and increase in instances of evaporation.

Determining the best trees for the city is depending on the climate of the location. In the mid latitudes, deciduous trees are beneficial as they shade during the summer and in the winter the bare trees allow for an UHI magnitude to make the city warmer and increase the thermal comfort for its residents. In tropical climates trees that are able to withstand the harsh conditions of the dry season are a more prominent consideration. In tropical climates shading is best on the roofs and along the north and western walls of buildings [12].

Shading is not the only area of consideration when dealing with urban trees as plants also have the capacity for sequestering carbon and filtering particles from the air particularly vehicle emissions. In a study to examine the proximity of a tree to the roadside and the amount of dust particles found on the tree it was noted that trees nearer to the road side were found with greater amounts of dust particles which highlights the abilities of trees to reduce the airborne particles in the urban canopy layer $[13,14]$.

\subsection{Green roofs}

It is plausible for roofs to represent a maximum of $32 \%$ of the built areas in urban settings and they are important source of radiation absorption into a particular building. They are also a key element of the impacts of UHI in the urban boundary layer. Green roofs can lower the heat transferred to the building by increasing the surface albedo of the surface and evaporation of the radiation for the sun before it can penetrate the building.

\subsubsection{Extensive vs. intensive}

There are two different categories of green roofs that can aid in the reduction of the effects of UHI. Extensive green roofs are more effective as there are shallow and low growing requiring minimal maintenance. There are mainly functional and provide greater surface areas in thermal protection from the sun's radiation. Due to their configuration, they are more lightweight and require less irrigation. Intensive green roofs are the more traditional form of roof top gardens and provide more of an aesthetical benefit to the roof top [15]. They contain more shade trees requiring deeper substrates to accommodate for roots. As more soils is needed, the weight of intensive roofs has to take into account the load on the building. They also require more maintenance and irrigation.

In urban settings the use of green roofs have indicated as much as a 2 degree reduction in temperature when used on at least $50 \%$ of the buildings. Green roofs have also encourage the emergence of insects and the ability to attract avrian species as they use the roofs to nest [16] improving the natural ecosystem in urban settings.

A green network is created in an urban setting when the inclusion of street trees, parks and green roofs exist in a contiguous pattern throughout the urban 
fabric. Balance in the urban setting and reduction in the magnitude of UHI can be achieved with green network projects to provide coverage for all areas impacted by anthropogenic activity.

\section{Conclusion}

The inclusion of green spaces within an urban setting can place an integral role in reducing the impact of UHI. In obtaining ways for alleviating the impacts of UHI without extensive resources to run scientific examinations the following process can be utilized:

1. Understand the impacts of UHI - how geography, energy use and transportation habits can impact the UHI magnitude with the urban canopy layer of the urban areas

2. Establish a metric - determine the characteristics of LCZ to guide an estimation of the UHI magnitude

3. Develop a strategy to reduce the UHI magnitude- inclusion of trees within the urban canopy layer and the urban boundary layer can make integral improvements in quality of air

As cities experience exponential growth, the negative impacts on the natural environment are becoming an increasing challenge. These impacts also affect the health and well-being of the residents within the urban setting. Steps towards restoring the native fauna can provide health and well-being benefits by reducing the impact of UHI.

\section{References}

[1] Voogt, J. A. Urban heat islands: hotter cities. America Institute of Biological Sciences, 2004.

[2] Benedict, M. A., \& McMahon, E. T. Green infrastructure. Island, Washington, DC, 2006.

[3] Taha, H. Urban climates and heat islands: albedo, evapotranspiration, and anthropogenic heat. Energy and buildings, 25(2), 99-103, 1997.

[4] Oke, T. R. The distinction between canopy and boundary-layer urban heat islands. Atmosphere, 14(4), 268-277, 1976.

[5] Sheffield, P. E., Knowlton, K., Carr, J. L., \& Kinney, P. L. Modeling of regional climate change effects on ground-level ozone and childhood asthma. American journal of preventive medicine, 41(3), 251-257, 2011.

[6] Sanhueza, P. A., Reed, G. D., Davis, W. T., \& Miller, T. L. An environmental decision-making tool for evaluating ground-level ozonerelated health effects. Journal of the Air \& Waste Management Association, 53(12), 1448-1459, 2003.

[7] Stewart, I. D., Oke, T. R., \& Krayenhoff, E. S. Evaluation of the 'local climate zone' scheme using temperature observations and model simulations. International Journal of Climatology, 34(4), 1062-1080. doi: 10.1002/joc.3746, 2014. 
[8] Oke, T. R., \& Stewart, I. D. Local Climate Zones for Urban Temperature Studies. Bulletin of the American Meteorological Society, 93(12), 18791900. doi: 10.1175/BAMS-D-11-00019.1, 2012.

[9] Green Infrastructure Overview. American Society of Landscape Architects. Retrieved from http://www.asla.org/ContentDetail.aspx ?id=43532, 2015.

[10] Akbari, H. Shade trees reduce building energy use and $\mathrm{CO}$ emissions from power plants. Environmental pollution, 116, S119-S126, 2002.

[11] Yu, C., \& Hien, W. N. Thermal benefits of city parks. Energy and Buildings, 38(2), 105-120, 2006.

[12] Environmental Protection Agency. (2015, March 27). Cool Paves Compendium. Retrieved from Environmental Protection Agency - Heat Island Resources: http://www.epa.gov/heatisland/resources/pdf/CoolPaves Compendium.pdf

[13] Matzka, J., \& Maher, B. A. Magnetic biomonitoring of roadside tree leaves: identification of spatial and temporal variations in vehicle-derived particulates. Atmospheric Environment, 33(28), 4565-4569, 1999.

[14] Smardon, R. C. Perception and aesthetics of the urban environment: Review of the role of vegetation. Landscape and Urban Planning, 15(1), 85-106, 1988.

[15] Oberndorfer, E., Lundholm, J., Bass, B., Coffman, R. R., Doshi, H., Dunnett, N., Rowe, B. Green roofs as urban ecosystems: ecological structures, functions, and services. BioScience, 57(10), 823-833, 2007.

[16] Macivor, J., \& Lundholm, J. Insect species composition and diversity on intensive green roofs and adjacent level-ground habitats. Urban Ecosystems, 14(2), 225-241. doi: 10.1007/s11252-010-0149-0, 2011. 